\title{
La educación saboteada y otras paradojas de los gobiernos de izquierda en Uruguay: ¿hacia un cambio de gobierno?
}

\author{
Saboted education and other paradoxes of the governments of left in
}

Uruguay: towards a government change?

\section{A educação sabotada e outros paradoxos da esquerda no Uruguai: para uma mudança de governo?}

\author{
Adriana Marrero' \\ Universidad de la República, Departamento de Sociología, Profesora titular. \\ https://orcid.org/0000-0003-0783-5775
}

“Educación, educación y más educación. [...] Dejáte de enseñarme 'viru viru' de carácter intelectual. [...] No estoy en contra de todos los académicos. [...] No hago votos por un país académico." José Mujica

Resumen: La educación pública, laica y gratuita ha sido uno de los pilares sobre los que se ha construido el Uruguay desde finales del siglo XIX. Sin embargo, los datos censales de 1963, mostraron una realidad que era ignorada por los uruguayos: la educación pública no alcanzaba a toda la población y sólo la mitad de la población adulta había terminado la primaria completa. Desde entonces, se ha ampliado la cobertura, pero paradójicamente, a un paso mucho más lento que el resto de los paises de Latinoamérica. En este contexto, se esperaba que los gobiernos de izquierda imprimieran un nuevo impulso a la educación: el presupuesto educativo pasó de $28 \%$ a más del $5 \%$, el salario docente se duplicó en términos reales, las instalaciones edilicias mejoraron y disminuyó el número de estudiantes por clase. Pero los resultados no mejoran: sólo un tercio de los jóvenes culminan la educación media. A partir de un breve relato histórico, se examinarán dos universos simbólicos que han estructurado los discursos educativos de la izquierda y la derecha en la última década. Sostendremos que la respuesta al problema educativo está dada por confluencia paradójica entre los efectos prácticos de un discurso proveniente de la izquierda, que procura imponer su visión desvalorizada de la educación, con consecuencias conservadoras, y un discurso de derecha autoritario, y sin embargo victimista, que dice querer restablecer -junto con aspectos del orden simbólico tradicional que la izquierda ha logrado revertir- la importancia de la educación pública en todos sus niveles.

Palabras clave: Educación pública. Discurso político. Uruguay.

Doctora en Sociología por la Universidad de Salamanca; Magister en Educación (Ciep-IDRC). 
Abstract: Public, secular and free education has been one of the pillars on which Uruguay has been built since the end of the 19th century. However, the census data of 1963, showed an unknown reality: public education did not reach the entire population and only half of the adult population had finished primary school. Since then, coverage has been expanded, but paradoxically, at a much slower pace than the rest of Latin American countries. In this context, leftist governments were expected to give a new impetus to education. In fact, the educational budget increased from $2.8 \%$ to more than $5 \%$, the teaching salary doubled in real terms, the building facilities improved and the number of students per class felt. However, the results do not improve. only one third of young people complete secondary education. From a brief historical account, two symbolic universes that have structured the speeches of the left and the right in the last decade in Uruguay will be examined, in particular reference to education. We will argue that the answer to the educative question is given by paradoxical confluence between the practical effects of a discourse from the left, which seeks to impose its devalued vision of education with conservative consequences, on one hand, and, on the other, an authoritarian right discourse, and yet victimist which says it wants to restore - along with aspects of the traditional symbolic order that the left has managed to reverse - the importance of public education at all levels.

Keywords: Public Education. Political Speech. Uruguay.

Resumo: A educação pública, laica e gratuita tem sido um dos pilares sobre os quais o Uruguai foi construído desde o final do século XIX. No entanto, os dados do censo de 1963 mostraram uma realidade ignorada: a educação pública não atingiu toda a população e apenas metade da população adulta havia concluido o ensino fundamental. 0 bacharelado e a universidade alcançaram apenas a elite. Desde então, a cobertura foi ampliada, mas paradoxalmente, em um ritmo muito mais lento que o resto dos países da América Latina. Nesse contexto, esperava-se que os governos de esquerda dessem um novo impulso ao educação. De fato, o orçamento educacional aumentou de 2,8\% para mais de $5 \%$, o salário de ensino dobrou em termos reais, as instalações do prédio melhoraram e o número de alunos por turma caiu. No entanto, os resultados não melhoram: apenas um terço dos jovens conclui o ensino médio. A partir de um breve relato histórico, serão examinados dois universos simbólicos que estruturaram os discursos de esquerda e direita na última década no Uruguai, em particular as referências para a educação Argumentaremos que a resposta ao problema educativo é dada pela confluência paradoxal entre os efeitos práticos de um discurso da esquerda, que busca impor sua visão desvalorizada da educação, com consequências conservadoras, e um discurso autoritário da direita, e ainda vitimista, que diz que deseja restaurar - juntamente com aspectos da ordem simbólica tradicional que a esquerda conseguiu reverter - a importância da educação pública em todos os níveis. Palavras-chave: Educação pública. Discurso político. Uruguai.

Recebido em 13 de setembro de 2019 Aceito em 12 de maio de 2020 Publicado em 05 de junho de 2020 


\section{INTRODUCCIÓN}

En su obra "M'hijo el dotor"2 (1903), el dramaturgo uruguayo Florencio Sánchez condensa lo que era entonces y durante al menos un siglo más, en el imaginario uruguayo, el arquetipo de las aspiraciones paternas sobre el destino social de sus hijos con vistas al ascenso social. En la obra, de carácter costumbrista, se dirime el conflicto entre la tradicional ética del esfuerzo y el estudio como la única vía, estrecha, para el acceso a la élite económica, política e intelectual, y los nuevos modos de experimentar la recién ganada libertad que otorga la distancia respecto del hogar paterno. En los hechos, para bien o para mal, el arquetipo de llegar a tener un hijo "Doctor" orientó las estrategias familiares de clases medias urbanas y rurales uruguayas. Para quienes no se atrevían a aspirar a tanto, la esperanza de que sus hijos pudieran tener una mayor educación que ellos mismos, podía llegar a constituir el sentido de sus vidas, orientando sus prácticas, dando un destino a sus ahorros, inculcando en los hijos la necesidad de estudiar, con el apoyo -indudable- de la educación pública uruguaya, laica y gratuita. El título de la obra de Sánchez, "M'hijo el dotor", se ha vuelto en Uruguay una expresión, entre irónica y burlona, que corre de boca en boca, ya sea con envidia, o con resignación. El valor de la educación uruguaya ya no suscita unanimidad.

\section{LA EDUCACIÓN PÚBLICA URUGUAYA: ORIGEN, MITO Y REALIDAD}

En Uruguay, la educación, entendida sobre todo como escuela pública, se constituyó en el más importante y significativo componente del imaginario colectivo desde el último cuarto del siglo XIX. Como vehículo para la socialización de decenas de miles de inmigrantes que llegaron sobre todo de Europa, con lenguas y costumbres variadas, y a la vez como mecanismo de integración de niños de distinto sexo y clases sociales, la escuela pública se convirtió en el locus privilegiado para la construcción de una identidad ciudadana unificada y para el aprovisionamiento de los rudimentos lógico matemáticos, lingüísticos y culturales para la incorporación al mundo del trabajo y la producción de las nuevas generaciones de uruguayos.

La reforma escolar aprobada en 1877 a partir de un proyecto de José Pedro Varela, bajo la dictadura del Coronel Lorenzo Latorre, fue un pilar fundamental de un proceso intencionado de modernización racionalizadora, con el estado como garante de un orden social

"Mhijo el dotor" es la expresión fonética de "Mi hijo el doctor" de acuerdo al modo de habla popular. 
secular e institucionalmente regulado. La reforma estableció una estructura centralizada y jerarquizada, al vértice de la cual se encontraba el Inspector Nacional de Instrucción Primaria, una Dirección General integrada por siete miembros y autoridades departamentales según la ubicación de la escuela. A partir de entonces, el estado sustraía a los padres el derecho de elegir si enviar o no a sus hijos a la escuela, al convertirla en obligatoria. A fin de sentar las garantías para dicha obligatoriedad, la escuela pública era, además, gratuita. Y aunque en un principio se incluía la enseñanza del credo católico -aunque los padres podían oponerse a que sus hijos la recibieran- muy pronto la escuela valeriana pasó también a ser laica. Si el propósito de la escuela era integrar, nadie debía sentirse incómodo recibiendo clases de una religión que no profesaba.

Junto a la reforma escolar vareliana, la creación del Registro Civil -que tenía como propósito generar una información sobre nacimientos, defunciones y matrimonios estatal, al margen de la lglesia Católica-, y el ordenamiento de la campaña a través del alambramiento y regularización de la propiedad de la tierra, fueron las principales bases para iniciar el proceso de desarrollo económico de inicios del siglo XX.

La educación pública uruguaya tiene sus primeros cambios institucionales en las primeras décadas del siglo XX. En 1918 se crea el Consejo de Enseñanza Primaria y Normal de cuya mano da inicio a un proceso vigoroso de experimentación e innovación pedagógica, sobre todo en Montevideo, que muy pronto dio sus frutos: Entre 1900 y 1943, la matrícula de la escuela pública pasó de 50.000 a 245.000 alumnos, multiplicándose por cinco. Mientras tanto, la población sólo se multiplicaba por dos, alcanzando a dos millones de habitantes al final del período. El resultado más evidente de esta expansión, fue el rápido abatimiento del analfabetismo: Mientras que según el censo de 1908, el porcentaje de analfabetos alcanzaba al $35 \%$ de la población, en 1963 , se situaba en algo más del $9 \%$, con lo que Uruguay ocupa una situación de privilegio no sólo en el contexto latinoamericano. En los censos siguientes, el analfabetismo seguiría bajando significativamente, hasta ubicarse actualmente en $1,5 \%$. A nivel de la enseñanza media, en 1912 se crean los liceos departamentales en todo el país y un liceo "femenino". En 1919 se crea un liceo nocturno, destinado a personas trabajadoras. A raíz de estos cambios, la matrícula en secundaria pasa de 500 estudiantes a fines del siglo XIX, a 6.300 en 1923 y a 11.360 en 1931. En 1935 la educación secundaria adquiere carácter autónomo, al separarse de la universidad, a la que pertenecía. En 1950, Uruguay tenía 300.000 estudiantes matriculados en enseñanza secundaria y era el país con mayor PBl per cápita de América Latina. La educación técnica, orientada a personas de bajos recursos, no tuvo una expansión proporcional y aún hoy se encuentra numéricamente muy rezagada en relación con la educación general de tipo intelectualista.

Durante las primeras décadas del siglo XX, la entonces llamada Universidad Mayor de la República, creada en la segunda década del siglo XIX, seguía siendo una institución 
pequeña y con escasa penetración social. Era una universidad de élite, en los hechos reservada a la formación de "doctores", aunque en la práctica, cumplió con un importante papel en la introducción y difusión de ideas políticas y económicas innovadoras, que, entre otros factores incidirían en la separación de la Iglesia y el Estado en la Constitución de 1919. Institucionalmente, vale la pena señalar la creación, en 1949, del Instituto de Profesores "Artigas", encargado ahora de la formación de docentes para la enseñanza secundaria, que antes se encontraba en manos de la propia universidad.

El vértigo legislativo, sobre todo en materia social, laboral y de derechos de las mujeres, que caracterizó el inicio del siglo XX uruguayo, de la mano del dos veces Presidente de la República José Batlle y Ordóñez, y el optimismo que se vivía a raíz de la multiplicación de los empleos por la creación de numerosos entes industriales en manos del estado, en un país agroexportador para países dos veces en guerra, no permitieron advertir los problemas que empezaban a asomar en el joven sistema escolar. Tuvo que pasar la crisis de la segunda postguerra mundial, una la reforma monetaria y cambiaria y la firma de una carta intención con el Fondo Monetario Internacional en 1959 para que, en 1963, pudiera aplicarse un nuevo censo nacional de población, que no se realizaba desde 1908.

El censo, cuyos datos fue analizado por un grupo de jóvenes intelectuales de la época, coordinados desde la $\mathrm{CIDE}^{3}$ por su Director, Enrique Iglesias, mostró una realidad educativa inimaginable: Según el "Informe sobre el estado de la educación en el Uruguay" de 1965 , más del $10 \%$ de la población carecía de instrucción y casi un $50 \%$ no había completado la enseñanza primaria. A mitad del siglo, sólo el 33\% había logrado terminar los seis años de escuela primaria. Recién en 1963 , los niños que terminaban la escuela alcanzaron el $60 \%$ :

\footnotetext{
La escuela uruguaya es actualmente inadecuada para superar los factores que inciden en ella. Su eficacia pedagógica y cultural se compromete día a día al no crear nuevos tipos de enseñanza para esta realidad en la que está inscripta". "En la enseñanza media la repetición es un fenómeno de entidad más intenso en la enseñanza técnica que en la secundaria; mientras que en este nivel la expansión demográfica estudiantil ha afectado la calidad de los servicios, haciendo inadecuados los equipos y exigiendo la utilización de personas sin la conveniente preparación previa como personal docente. La masificación de la enseñanza ha llevado hasta las aulas a alumnos provenientes de medio socio-culturales más pobres [...] sin que el sistema creara condiciones de mayor intensidad educativa que, compensando las diferencias de origen, volvieran reales las iguales posibilidades que la sociedad debe ofrecer a todos los niños [...] (CIDE-CCEE, 1965, p. 18).
}

\footnotetext{
Comisión de Inversión y Desarrollo Económico, oficina precursora de la Oficina de Planeamiento y Presupuesto, Presidencia de la República.
} 
En el mismo sentido, otro trabajo (RAMA, 1971, p. 109), señala que, en 1950, menos del $40 \%$ de los uruguayos lograban terminar los seis años de escuela. La expansión del sistema, tal como fue mostrada antes, obedecía más a la incorporación de los niños en los primeros años, que a la retención y al tránsito de la población escolar hacia grados superiores como consecuencia de la acción educativa de la escuela. La repetición, la extra edad y la permanencia en la escuela durante años sin lograr egresar, fue una constante de la educación uruguaya hasta bien pasada la mitad del siglo XX:

\begin{abstract}
Para todo el pais, en 1934, había un $37.8 \%$ de repetidores en la matrícula de $1^{\circ}$ año: en 1967 ya estaba en 33.8\%. Para todo el sistema, es decir, para los seis años, en 1964 de cada 100 niños matriculados, 24 son repetidores. Como los niños estaban en la escuela un mínimo de cinco años y generalmente el $90 \%$ estaba por lo menos seis años, pero estaba varios años para realizar dos o tres cursos, al bajar la tasa de repetición ha mejorado inmediatamente la distribución por cursos [...] (RAMA, 1971, p. 112).
\end{abstract}

Otro texto de CEPAL, de casi veinte años después, reitera el mismo fenómeno: El censo de 1963 mostró que la mayoría de la población de Uruguay tenía primaria incompleta. Recién en 1967, se incluye el ciclo de seis años en las escuelas rurales. La escuela primaria recién alcanza la universalización en 1985, en el año de recuperación de la democracia después de 12 años de dictadura (CEPAL, 1990, p. 16). El éxito de la escuela pública, indudable en el logro de la alfabetización, no pasaba la prueba del egreso, e impedía en los hechos que los niños y jóvenes uruguayos pudieran progresar hacia niveles superiores de escolarización.

La razón por la cual se ha mantenido, a través de las décadas, el mito de que la educación pública uruguaya de mediados de siglo XX lograba niveles de excelencia, dignos de ser añorados y reiterados, es una especie de misterio. Posiblemente Uruguay, un país tan pequeño en medio de países de las dimensiones geográficas, demográficas y económicas tan colosales como Brasil y Argentina, necesitó de una frondosa mitología para convencerse de la razón de su existencia. Lo cierto es que educación pública de excelencia, es todavía, pese a todas las evidencias, una de las razones por las cuales seguimos diciendo a menudo que "como Uruguay, no hay".

A partir de 1989, otros diagnósticos, también adversos, llevados a cabo por CEPAL por encargo de ANEP ${ }^{4}$ sobre enseñanza primaria, ciclo básico y bachillerato, sentaron de una vez por todas la hipótesis de que el factor más determinante de la desigualdad educativa, era la desigualdad socioeconómica. Desde primaria al bachillerato el sistema educativo parecía 
hacer poco más que ratificar con sus resultados y legitimar con sus credenciales el origen social de los estudiantes.

En 1995, con la llegada del ex director de CEPAL, Germán Rama, a la Presidencia de la ANEP, de la mano del Partido Colorado y de una nueva Presidencia del Dr. Julio Ma. Sanguinetti, se puso en marcha una ambiciosa reforma educativa que, sin embargo, no contó con el apoyo financiero suficiente como para poder aplicarse a cabalidad y en todos los institutos del país. La feroz resistencia de los sindicatos de la enseñanza a la reforma, un tanto incomprensible, dado su carácter estatista y su preocupación social, fue un elemento definitorio en su suerte final. En régimen de experiencia parcial, la "Reforma Rama" no perduró. Con el advenimiento del Frente Amplio al poder, luego de la crisis económica y financiera que sufriera el gobierno colorado de Jorge Batlle en 2002, la debilitada reforma fue dejada de lado. El Frente Amplio tenía su propio programa de mejora para la educación. ¿̇0 no?

Pues no.

Si de algo se enorgullecía la izquierda, antes de su llegada al poder, era la de contar con más destacadas figuras de la intelectualidad uruguaya. Como toda sociedad que mira a un puerto, y que organiza en torno a él la actividad económica, política y cultural, termina concentrando en su entorno, la efervescencia y frescura de las ideas nuevas. A comienzos del siglo XX, Montevideo era una pequeña ciudad puerto, de talante liberal, con fuertes pretensiones modernizadoras y hegemónicas respecto de la campaña, primitiva y feraz que presentía a sus espaldas. Derrotada la insurgencia rural, la capital se convirtió en centro de la innovación política, ideológica y social. Las élites políticas e intelectuales, eran, decididamente, progresistas, tal como lo atestigua la avanzada legislación de inspiración socialista.

Esta tradición, que continuaría a través de todo el siglo XX, sólo se vio dramáticamente interrumpida durante la dictadura militar, que diezmó los cuadros intelectuales, sobre todo los dedicados a la educación y a la enseñanza, ya sea a través de la persecución, el exilio o la muerte. La restauración democrática, y el ascenso de las izquierdas en el firmamento político, parecían prometer una era de avances educativos y culturales. Contra todo pronóstico, ello no ocurrió.

\section{LA IZQUIERDA EN EL PODER: 2005-2019}

Cuando en 2005 el Frente Amplio gana el gobierno de la mano de Tabaré Vázquez, se espera con gran interés, los nombres de las figuras que han de guiar el nuevo rumbo de la educación. Cuando los nombres salen a luz, se produjo el desconcierto. Jorge Brovetto, ingeniero, ex Rector de la Universidad de la República, es nombrado Ministro de Educación y Cultura. Para presidir el Consejo Directivo de la ANEP, se designó a Luis Yarzábal, médico, 
cuyo antecedente profesional más cercano consistía en investigaciones inmunológicas con población indígena de la selva amazónica venezolana. Su conocimiento del sistema educativo que le tocaba gobernar era, como mucho, epidérmico. Brovetto, que también desconocía casi todo de la educación no universitaria, lanzó desde el MEC el proyecto de llevar a cabo un "Debate Educativo" donde toda la sociedad discutiera libremente sobre los fines de la educación y los modos de llegar a ellos.

Organizado sobre una base territorial que tomaba como referencia los centros educativos, sin participación de los medios -que habían tenido un papel tan central en la Reforma Rama- sin debates de expertos en educación que pudieran ser trasmitidos por TV, radio o internet, con el fin de centrar los ejes del intercambio y elevar la perspectiva para la elaboración de propuestas, el debate no arrojó resultados ni ideas que calaran en el ánimo de la población. Las reuniones que se convocaban en escuelas y liceos, a las que asistían sobre todo padres y vecinos versaban, bien sobre la reposición de los vidrios de las aulas, bien sobre cómo conseguir pintura para las paredes, mientras algún pedagogo trataba de intercalar una cita de Paulo Freire y una maestra evocaba palabras de Luisa Luisi. ${ }^{5}$ Quien tuviera algún documento sobre educación podía enviarlo a la Comisión Coordinadora, que debía incluirlo entre los materiales. El debate culminó con Congreso con participación de unos 1200 delegados, que reclamó "un nuevo Sistema Nacional de Educación público, estatal, autónomo y cogobernado" y un presupuesto no menor al $6 \%$ del PBI.

Pero curiosamente, las medidas más relevantes del período, no pasaron por el famoso "debate". Ya en el mensaje presupuestal de 2005, en el primer año de gobierno, se incluyeron 16 proyectos educativos. Se crea Agencia Nacional de Investigación e Innovación (ANII), bajo el contralor administrativo del MEC, con el propósito de preparar, organizar y administrar proyectos y programas para la promoción y el fomento del desarrollo científicotecnológico y la innovación, y que hoy en día cumple un papel de primera importancia en el financiamiento de todo tipo de proyectos académicos y productivos. Mayor destaque internacional tuvo el Proyecto CEIBAL (Conectividad Educativa de Informática Básica para el Aprendizaje en Línea) que se lanza en abril de 2007, en base a las computadoras de bajo costo producidas por el Instituto Tecnológico de Massachussets (MIT). El proyecto otorga una computadora portátil a cada niño que asiste a escuelas públicas, y más tarde, se extendió también a la educación media. Su objetivo es el logro de la igualdad de oportunidades en el acceso a la tecnología, la democratización del conocimiento y potenciación de los aprendizajes en el ámbito escolar y en el contexto vivencial de los alumnos. Finalmente, en el año 2008, se aprueba una nueva Ley General de Educación, que crea nuevos Consejos en la órbita de ANEP, además de otras innovaciones.

Luisa Luisi Janicki (Paysandú, 1883 - Santa Lucía, 1940). Poeta, pedagoga y crítica literaria uruguaya. 


\section{LOS RESULTADOS}

El gobierno de izquierda no dudó en mostrar su compromiso presupuestal con la educación pública, durante los tres períodos de su gestión. Desde el 2005, la inversión pública en educación pasó de 3,1\% al 5,14\% del PBI, logro sobresaliente, si se toma en cuenta que el producto, en el mismo período, se multiplicó por tres. El salario real docente creció un $90 \%$ y la inversión por estudiante aumento un $244 \%$. Se amplió en número de docentes y de funcionarios de la educación al reducir significativamente el número de estudiantes por aula. Se redujo la brecha digital, y se incrementó significativamente la conectividad escolar. Se alcanzó la mayor inversión en infraestructura de la historia: Sólo en los tres primeros años de gobierno del FA, se construyeron 38 nuevos edificios, se ampliaron 291 y se realizaron 3.333 obras de mantenimiento. Se introdujo inglés en todas las escuelas primarias del país y se universalizó el acceso a la educación media. Se financian los boletos de transporte gratuitos a todos los estudiantes de primaria, ciclo básico y bachillerato. Las propuestas curriculares de las escuelas técnicas ascendieron a 245. Se creó una nueva universidad, (la Universidad Tecnológica del Uruguay, UTEC) en el interior del país. Además, se creó la Biblioteca Ceibal, que permite el acceso a más de 4.000 en forma gratuita a toda la población.

Este enorme avance presupuestal no estuvo acompasado, sin embargo, con una mejora de los desempeños estudiantiles, sin importar a través de qué indicador se lo mida. Desde el punto de vista del tránsito por el sistema, las tasas de egreso siguen siendo desalentadoras. Desde el punto de vista de los aprendizajes, medidos por las pruebas PISA o por las pruebas que aplica el Instituto Nacional de Evaluación Educativa (INEEd), también son insatisfactorios y se encuentran estadísticamente asociados con el nivel socioeconómico del hogar.

Según el informe elaborado por el INEEd (Instituto Nacional de Evaluación Educativa) para los años 2017 y 2018, se sigue adjudicando a la falta de políticas educativas adecuadas el bajo egreso de la educación media superior. Sólo una cuarta parte de los jóvenes culmina la educación media a los 18 años. A los 19 años, edad teórica en la que todos los estudiantes deberían haber egresado del bachillerato, un $22 \%$ se encuentra rezagado, y un $42 \%$ ya abandonó el sistema educativo. A los 23 años, el porcentaje de egreso sólo llega al 43\%, lo que coloca a Uruguay en el fondo de la tabla en comparación con los demás países de la región. En cuanto a los docentes, se constata que presentan trayectorias educativas menos regulares y satisfactorias que los coetáneos universitarios. En primaria, durante 2017, se perdieron unos veinte días de clases por inasistencia docente. En la Educación Media, dejaron de producirse cifras, pero llegó a oscilar en un tercio del total de clases posibles. Finalmente, el informe da cuenta de que "el sistema educativo no cuenta con información precisa de 
cuántos ni cuáles alumnos tienen necesidades educativas especiales, ni cuenta siempre con un diagnóstico sobre cada estudiante." (INEEd, 2019, p. 137).

El informe del INEEd no cayó bien entre las autoridades de ANEP. El presidente del CODICEN de ANEP, Wilson Netto, que había solicitado, sin éxito, que se postergara la presentación del informe por razones electorales, criticó el informe. Dijo que es "incoherente", que "no aporta", y que no reconoce los logros de las políticas aplicadas. Hace dos años, cuando se presentó el informe anterior, Netto simplemente no concurrió a la presentación de un documento que, según sabía, no lo iba a dejar bien parado.

\section{LA IZQUIERDA URUGUAYA, EL “DESPOTISMO ILETRADO” Y EL UIRU UIRU}

Uno de los cambios más notorios en la cultura política del país durante el gobierno de izquierda, fue la aparición de un nuevo tipo de dirigente que venía a poner en cuestión el modelo de político profesionalmente formado en alguna carrera universitaria, en particular, en la Abogacía. Como se decía al inicio del artículo, el imaginario social uruguayo asociaba la práctica política y la pertenencia a las élites intelectuales con la figura del "Doctor". Versado en leyes, conocedor de la Constitución, diestro en la técnica legislativa, este tipo de político profesional constituía el núcleo duro de la dirigencia partidaria, en particular de los partidos tradicionales, el Partido Nacional, de origen rural, nacionalista y conservador, y el Partido Colorado, urbano, cosmopolita y liberal. En estos casos, la práctica política podía deslizarse, bien hacia la tentación tecnocrática, bien hacia un cierto autoritarismo político con reminiscencias de "despotismo ilustrado". La izquierda, menos seducida por la tecnocracia, pudo haber resbalado, sin embargo, hacia una forma nueva de despotismo: el "despotismo iletrado".

En su libro "7 patologías de la izquierda", Mirza (2019) identifica entre ellas, al "despotismo iletrado". Jugando con la expresión "despotismo ilustrado" que se usaba para describir las monarquías absolutas europeas previas a las revoluciones burguesas, Mirza - que ocupó cargos de confianza en el gobierno del Frente Amplio y sigue perteneciendo a élmuestra cómo es posible actuar despóticamente, no en base a la invocación del conocimiento o de unas ideas técnicamente "indiscutibles", sino, contrariamente, oponiéndose a cualquier tipo de conocimiento científico y filosófico como base y orientación para la acción política:

\footnotetext{
[...] en este tipo de patologías se desdeña el conocimiento científico y las capacidades o habilidades desarrolladas a consecuencia de estudios o formación de nivel superior [...] Ahora son los universitarios o los que cuentan con acumulaciones sistemáticas en un dominio específico del
} 
conocimiento los desdeñados o subvalorados. [...] apelando a la "universidad de la calle" desdeñan el conocimiento adquirido y construido colectivamente [..] para resolver los problemas contemporáneos de los ciudadanos y ciudadanas que así lo esperan. De tal modo que, ante una recomendación o propuesta formulada por los profesionales se los cataloga de tecnócratas o intelectuales sin experiencia en las lides de la política. (MIRZA, 2019, p. 48).

No creemos difícil encuadrar dentro del concepto de "despotismo iletrado", muchos de los fenómenos que analizaremos a continuación, y que son característicos, sobre todo, de los últimos dos períodos del gobierno del FA. Básicamente, me propongo mostrar cómo, desde un saber pretendidamente popular, que tanto en sus formas como en sus contenidos enrostra a la sociedad su desprecio manifiesto hacia todo pensamiento cultivado o complejo, hacia un vocabulario rico, preciso o sofisticado, y en general, hacia todo lo académico, el déspota iletrado pretende ocultar su primacía personal, la eficacia de su poder de base carismática, y su orgullo cuando no, su soberbia. Proveniente de la "universidad de la calle", su conocimiento es más valioso y práctico que el generado en las "torres de marfil" universitarias, y por ello, debe prevalecer.

Esta es, claro está, una dicotomía que no se sostiene. En un sistema universitario gratuito y de libre ingreso, la universidad está lejos de ser un ámbito aristocrático, vedado para personas de clases bajas, que pudieron ingresar a ella y sin embargo también conocen los penares económicos y sociales de la vida cotidiana. Pero, además, por las disciplinas que se imparten en la supuesta "universidad de la calle", no suelen circular conocimientos novedosos o vanguardistas, sino poco más que viejos prejuicios muchas veces contradictorios entre sí, casi siempre conservadores, sustentados en la supremacía de la fuerza física o en la simple viveza criolla.

La ignorancia es la fuente de inspiración del despotismo iletrado, y la soberbia, lo que la sostiene. Es por ello que, el debate libre y desprejuiciado se hace imposible [...] Aquellos que se dignan criticar o simplemente advertir los actos reflejos que conlleva el despotismo iletrado, son inmediatamente desterrados, condenados al ostracismo $\circ$ incluso, denunciados por no comprender la racionalidad detrás de las narrativas populares (èpopulistas?) y acusados de ser elitistas divorciados de la realidad. [...] "Inevitablemente se degrada la función pública, en la medida que todas las decisiones pasan por el filtro del déspota iletrado, donde su autoridad [...] se sostiene o se funda en sus prejuicios, desconocimiento, o estereotipos. Nadie puede $\circ$ debe contradecir las decisiones del déspota iletrado, a cuya sujeción se deben todos los subordinados. (MIRZA, 2019, p. 49-50). 
Como lo describe Mirza con lucidez y agudeza, desde la pertenencia a la propia fuerza política, este fue el talante que se impuso en un debate público languideciente por falta de argumentación y racionalidad, hegemonizado por el Frente Amplio.

\section{UN PARLAMENTO POCO LETRADO}

Con el advenimiento del Frente Amplio al poder, en el año 2005, no hubo cambios demasiado evidentes; al menos no en el primer período. Habiendo ganado con mayoría absoluta en las elecciones del 2004, y luego también con mayoría absoluta del legislativo en 2009 y 2014, la fuerza de izquierda comenzó a cambiar el perfil del parlamento nacional. A diferencia de los partidos tradicionales, la nueva fuerza mayoritaria llevó al Poder Legislativo a un conjunto dispar de personas reclutadas de la dirigencia sindical, de la militancia política y del activismo social ligado al territorio, que poco se parecían, incluso a simple vista al viejo modelo del profesional universitario, de traje y corbata. Pero esto no ocurrió de repente, sino que fue conformándose poco a poco después de que, diez años antes, en 1994, quien luego fuera Presidente de la República, el entonces Diputado José (Pepe) Mujica, diera un simbólico puntapié inicial en la impugnación de las maneras y del sentido común que había guiado a la vida parlamentaria en el pasado, al llegar a asumir su cargo de Diputado electo desastrado y empujando una motoneta. Se dice que los porteros del Palacio lo confundieron con un mensajero y le preguntaron: "ỉSe va a quedar mucho rato, señor?". Esta historia, que no es cierta, fue divulgada, con motivos publicitarios, para subrayar el carácter de "outsider" y, por tanto, "puro" de Mujica como político. Su pasado guerrillero, al parecer, no importaba.

De ahí en adelante, el vestir descuidado, si es posible usando prendas que servían como "marca de clase popular", tal como usar una cuerda en lugar de cinturón, al uso de los obreros de la construcción, fue un estilo adoptado con desafiante orgullo por los nuevos legisladores frenteamplistas. El lenguaje, también cambió, la gesticulación, y en general, se adoptó una modalidad de que pretendía emular a aquella clase o sectores sociales a los que se pretendía representar. Salvo, claro está, a las mujeres, que apenas llegaban a superar el $10 \%$ del total de parlamentarios.

La conformación del parlamento que surgió de las elecciones nacionales de 2014, tuvo ecos más allá de fronteras. El 9 de noviembre de ese año, el portal argentino Infobae informaba que, del total de los 129 legisladores electos, sólo 61 poseían un título universitario: 13 médicos, 6 contadores o economistas, 6 licenciados en distintas disciplinas, 5 ingenieros y 4 veterinarios, entre otras profesiones. Además, había un enólogo, un instalador sanitario y un mecánico. Pero, además, 
obsérvese que sólo $१ ८$ de los $१ २ ६$ legisladores eran abogados, y ninguno de ellos pertenecía al Frente Amplio, partido de gobierno, y poseedor de la mayoría parlamentaria.

Más allá del aspecto meramente descriptivo del fenómeno, la aparición de este funcionario relativamente "iletrado" tuvo un importante impacto, tanto en términos de técnica legislativa, como desde el punto de simbólico, como muestra de la desvalorización de la educación formal para el desempeño de tareas complejas, como lo es siempre, la elaboración de nuevas leyes.

Como se puede concluir, la bancada oficialista tenía la capacidad de elaborar y aprobar leyes, sin tener entre sus miembros ni a un solo experto en la materia. Aunque se contara con asesorías de parte de abogados pagados por las bancadas, esos abogados no se encuentran en sala al momento de los debates y no siempre podían estar al tanto de lo que se estaba votando. El resultado inmediato, fue una notoria sucesión de declaraciones de inconstitucionalidad de varias leyes, por parte de la Suprema Corte de Justicia. Las leyes, estaban mal elaboradas. Sin embargo, buena parte del elenco político oficialista, prefirió interpretarlo como una forma de oposición política por parte del Poder Judicial, y a su máximo órgano, cuyos miembros quedaban, de paso también, desacreditados (LA MITAD..., 2014).

\section{UNOS PROFESIONALES NO TITULADOS}

La desvalorización de los estudios formales, en especial los universitarios, y todas las profesiones y actividades académicas vinculadas a ellos, no fue sólo un epifenómeno derivado de la realidad de un reclutamiento de legisladores y otras autoridades de origen social menos privilegiado. Fue también una postura expresa que asumió oficialmente José Mujica durante su mandato, y su sector y otros sectores simpatizantes del mandatario durante todos los años de la hegemonía política frenteamplista.

No era, por supuesto, la posición de Tabaré Vázquez, de origen socialista, primer presidente de izquierda en 2004, y actualmente en su segundo período no consecutivo de gobierno. Vázquez, proveniente de una familia humilde en el barrio montevideano de La Teja, había apostado decididamente a la educación, había egresado como médico, y luego obtuvo una especialización en oncología. Además, había desarrollado carrera académica, llegando a ser catedrático de oncología en la Facultad de Medicina de la Universidad de la República, y a convertirse en un destacado especialista a nivel internacional. El tercer líder de izquierda, el economista Danilo Astori, Vicepresidente de Mujica y Ministro de Economía en los dos gobiernos de Vázquez, también había sido catedrático de economía en la Universidad de la República, y fue electo Decano de la Facultad de Ciencias Económicas, convirtiéndose en el 
Decano más joven de la historia de la Universidad. La izquierda tradicional, proveniente de aquel partido fundado en 1971, valoraba la educación, la ciencia, la tecnología y el conocimiento. La inflexión tuvo lugar con el advenimiento de los integrantes del Movimiento de Liberación Nacional (Tupamaros), o MLN, que fueron admitidos en el Frente Amplio en el año 1989.

Como parte de esta verdadera campaña desacreditadora del saber profesional y académico, tal vez sólo conducida por un encono personal, Mujica abundó en declaraciones en contra de profesionales de distintas ramas. Sólo a título de ejemplo, en 2013, en ocasión de un conflicto de la enseñanza por mayores recursos, consideró que las maestras trabajaban poco, "cuatro horas, 180 días al año" por lo que podían trabajar más ("te quedan otras horas para hacer otra cosa") para aumentar sus ingresos (MUJICA A LOS..., 2013). En 2014, opinó que era "un alivio" saber que la mitad de los legisladores no tenían títulos universitarios, ya que quienes estudian "porque saben algo se creen que lo saben todo. Y el que no sabe tiene la humildad de los que no saben." (LA FACULTAD..., 2011). En su audición radial, reafirmó sus palabras, agregando que él no está en contra de todos los académicos sino de los "arrogantes". Abundando sobre las malas cualidades de los académicos, Mujica se refirió también al "sueño de academia", que consistiría en lo perceptible socialmente: "el diletantismo, la arrogancia, que a veces aparecen" que sería una "arrogancia con tinte de nueva aristocracia".

\footnotetext{
Por eso hago votos por un Uruguay mucho más instruido y culto y ese es un caminito infinito, pero no hago votos por un país académico, arrogante, de los que no se dan cuenta que en última instancia lo poco que podemos llegar a saber debe estar al servicio de la gente por encima de todo lo demás. (LA FACULTAD..., 2011).
}

En otra ocasión, molesto por el análisis de coyuntura del economista Gabriel Oddone, consultor en uno de los estudios más importantes de Uruguay, Mujica declaró: "Estamos infestados de economistas, escribanos y abogados. Oddone no se subió en su vida a un arado ni en pedo" (MUJICA..., 2013), y a continuación: (son) "picapleitos que viven escudriñándose los intestinos al Estado y terminan en muchos casos robándole suculentas sumas." (MUJICA ACLARÓ..., 2013).

Si esto contribuyó a generar la idea en los sectores populares que su falta de educación, lejos de ser una carencia, era motivo de orgullo, hubo un episodio que fue altamente simbólico ante los ojos de los ciudadanos, sobre todo ante quienes conservaban la vieja idea de la educación como sustento de la ciudadanía y del trabajo: el caso del título de Licenciado del Vicepresidente de la República, Raúl Sendic.

Hijo del dirigente tupamaro Raúl Sendic, fallecido en 1989, Raúl Sendic (h) había pertenecido a un ala radical de izquierda. Cuando José Mujica accedió a la Presidencia, 
en 2010, Raúl Sendic (h) pasó a ocupar importantes cargos de gobierno, entre ellos, como Presidente del Directorio del más grande Ente público, la petrolera y cementera ANCAP. En las elecciones internas de 2014, su lista fue la más votada del Frente Amplio y eso fue decisivo para su inclusión en la fórmula presidencial que encabezaba Tabaré Vázquez, como Vicepresidente. La fórmula fue electa con mayoría absoluta de escaños parlamentarios, entre rumores de corrupción contra Sendic.

Pero lo que más alarmó a la ciudadanía apenas a unos meses de haber asumido el cargo, fue la noticia de que el título de Licenciado en Genética Humana que Sendic ostentaba, era falso. No sólo eso, sino que la Universidad de La Habana, donde decía Sendic que había cursado y obtenido su licenciatura, declaró que dicha licenciatura no existía, y que nunca había habido una licenciatura con tal denominación; que el expediente de Sendic era el de un estudiante de medicina con estudios inconclusos, y les expidió, a las periodistas encargadas de la investigación, un certificado completo con la escolaridad -bastante mediocre- de Sendic mientras estudió en la capital cubana.

La noticia escandalizó a muchos, no sólo porque entrañaba una mentira inconcebible para un Vicepresidente, sino porque, además, era uno de izquierda, hijo político de Mujica, a quien los uruguayos habían elegido sin reparar en títulos universitarios que nadie pedía. La sombra de la falta de honradez de Sendic, ya formada por los rumores de corrupción o al menos, de mal manejo de los fondos públicos durante su gestión en ANCAP, se oscureció de pronto. Para mucha gente, Sendic, debía renunciar o disculparse por haber mentido. Para algunos de sus votantes y simpatizantes, estudiar era de "privilegiados" y no tener un título no era importante. Lo que no se comprendía, o no se quería entender, era que no se trataba de tener o no una titulación, sino de adjudicársela sin tenerla.

Como se comprenderá, la mentira de Sendic generó una paradoja difícil de resolver. Si Mujica y todo su entorno no valoraban realmente los títulos universitarios, si no consideraban que ser profesional tuviera ventaja alguna, ¿̇por qué adjudicarse un título que no se tenía y que se estaba lejos de tener? Lucía Topolansky, entonces Senadora, esposa de Mujica, y estudiante en su juventud de Arquitectura, carrera que jamás finalizó, declaró en más de una entrevista: "yo vi el cartoncito", sin dejar lugar a dudas, con esto, lo que para ella era un título universitario: sólo "un cartoncito". Finalmente, después de mucho tiempo de negar la mentira, Sendic confesó que él se llamaba licenciado porque se sentía así.

No fue sólo Sendic quien expresara, con su mentira, la paradoja de pertenecer a una izquierda que aparentemente no valoraba los títulos, y la de pertenecer, al mismo tiempo, a un país que los valoraba más que a nada. Durante el período de gobierno que comenzó en el 2015, además del de Sendic, salieron a la luz otros casos de jerarcas estatales, todos del Frente Amplio, que habían mentido sus títulos: Gustavo Belarra se hizo pasar por sociólogo y terminó perdiendo su cargo en el Instituto Nacional de Rehabilitación; Gonzalo Reboledo, 
secretario político del Frente Amplio, también se había atribuido el título de Licenciado en Sociología, pero culpó a alguien más, y conservó su cargo; Eduardo de León, también se decía Sociólogo, y renunció a la Oficina de Planeamiento y Presupuesto, dependiente de Presidencia de la República. Por su parte, Lucía Anzalone, que se decía Psicóloga sin serlo, había sido contratada como tal por su propio hermano en el Ministerio del Interior. Dentro de sus funciones, estaba la selección del personal policial para ingresar a la fuerza. De todos quienes ostentaron títulos falsos, sólo Lucía Anzalone fue procesada y declarada culpable por usurpación de Título. Sendic fue también procesado, pero la tipificación del delito de "usurpación de títulos" lo excluía de esta forma delictiva: él se había adjudicado un título que no existe en Uruguay. Y tampoco en Cuba, por supuesto.

Como si todos estos episodios no hubieran sido suficiente para mostrar el uso desaprensivo que los dirigentes de la izquierda respecto de los títulos universitarios, fue nuevamente esa la primera noticia que se supo sobre la trayectoria de la candidata a la vicepresidencia de la República por la fuerza de izquierda, Graciela Villar: se había hecho llamar Licenciada en Psicología Social, y había figurado como tal en la página web de la Junta de Montevideo mientras era Edil, y en sus redes sociales. La polémica no duró mucho. Villar explicó en una entrevista televisiva que, debido a la dictadura, sólo había terminado tercer año de enseñanza media. Sobre cómo la dictadura pudo haber incidido en su decisión de hacerse llamar Licenciada, nada declaró, aunque admitió que pudo haber sido un error (GRACIELA VILLAR..., 2019).

\section{UNAS CIENCIAS UIRU UIRU}

Como es sabido, Mujica se caracterizó por un discurso marcado por expresiones folclóricas, por modos de hablar llenos de incorrección gramatical, por verbos mal conjugados y por la abundancia de neologismos. Tal vez el más reiterado haya sido la expresión "viru viru" que el ex Presidente usaba para referirse al conocimiento que emana de las ciencias sociales, humanas y artísticas. Para él, el mundo del conocimiento escolar parece dividirse en dos: por un lado, el que generan las ciencias físicas y naturales, y el uso de la tecnología. A los "pobres" les correspondería una enseñanza técnica, de tipo industrial, y de corta duración, que permitiera un acceso rápido de empleo. Por el otro lado, estaría el vasto y difuso mundo del "viru viru", cuyo ejemplo más notorio es el de las ciencias de la comunicación, pero en general, incluiría a todas las ciencias sociales y humanas y a las profesiones vinculadas con las letras, como la abogacía.

La inauguración de su neologismo tuvo lugar precisamente, en el acto de investidura de las autoridades de la educación de su gobierno, en marzo de 2010, cuando en 
su discurso pidió que no se le diera tanto "bombo" -como sinónimo coloquial de "importancia"a "un país de viru viru": "No se puede sacrificar oleadas de jóvenes que inocentemente van a estudiar Ciencias de la Comunicación. No se puede construir algo sólido si no se hace en derredor de las matemáticas y las ciencias." (“VIRU VIRU”..., 2011). De ahí en adelante, la expresión viru viru se convirtió en el modo en que Mujica se refería a todo conocimiento que él consideraba, por decirlo así, inservible, una pérdida de tiempo y de dinero:

"L...] asi como somos afectos a las letras y a todo lo que es 'viru viru', poco
afecto le hemos tenido a las matemáticas, a la física y a la química." ("VIRU
VIRU"..., 2011).
"dejáte de enseñarme 'viru viru' de carácter intelectual y enseñame cosas
que me sirvan para pelear por la vida." ("HAY QUE..., 2014).
"tenemos que disminuir enormemente la cuota de 'viru viru' y multiplicar la
capacidad del trabajo científico y técnico." (EL PAÍS..., 2014).
"No he visto a esta gente que hace viru-viru -los intelectuales-
arremangarse y comprar unos chorizos para compartir con los pobres."
(A PROPÓSITOS..., 2016).
"con interpelaciones no vuela la gente." "Lo único que hacemos es darle al viru
viru en el Parlamento y no solucionamos los problemas." (CONVOCARÁN..., 2012).

Es sencillo comprender el malestar que causaron estas consideraciones, repetidas y otra vez, en un ámbito académico dividido entre, por un lado, un apoyo hegemónico a la izquierda, y por otro, la alta conciencia que la tradición de izquierda siempre adjudicó a la importancia de la crítica filosófica en la transformación social. Entre los políticos profesionales, juristas y politólogos, fue una dura crítica que desvalorizaba sin más una práctica que contribuía a la calidad de la democracia y a la salud de la cultura. Fuera de la academia, para aquellos uruguayos que todavía aspiraban a tener un "hijo doctor", un simple descrédito a sus esfuerzos por dar a su descendencia una mejor educación. Sólo entre los nuevos "analfabetos funcionales" que generaba el sistema - la propia directora de primaria, Irupé Buzzetti llegó a afirmar que los niños salian a los 15 años de la escuela sin poder leer un diario- las palabras de Mujica expresó lo que ellos tal vez sentían: ser intelectual no tenía sentido alguno.

\section{LA DERECHA Y SUS ARMAS: UICTIMIZACIÓN, INCORRECCIÓN, MESIANISMO}

En un libro de reciente aparición (ENTRE, 2019), que analiza las estrategias y tácticas de la derecha uruguaya para mantener la hegemonía que de hecho ejercería, se parte del supuesto de que, "Lo más importante para la derecha es el orden. Si no lo hay, debe ser 
impuesto, y si existe y es desafiado, debe haber una reacción. [...] La derecha es la defensa de las jerarquías sociales, mientras que la izquierda es el cuestionamiento y el desafío de las jerarquías sociales." (ENTRE, 2019, p. 18). Según los autores del texto, en su búsqueda por mantener esa hegemonía y mantener el orden social que custodia, la derecha se vale de tres estrategias básicas: una gradación de las jerarquías y de la autoridad, de modo que cada uno pueda percibir con claridad quiénes y cuántos están por encima y por debajo en la escala social, una cooptación mínima de las masas por parte de las élites, que sirve como efecto demostración de las posibilidades de ascenso social meritocrático, y el sostén del deseo de dicho ascenso como medio de acceso al consumo y a mayores niveles de bienestar.

En muchas de las preocupaciones que le son características, como el orden, la preocupación por la normalidad y el combate a las "patologías", y la reserva de la educación en manos de las familias, en contra de la educación pública, laica y universalista de inspiración vareliana, la derecha ha encontrado, en el gobierno del Frente Amplio, varias líneas de diálogo con las clases populares. En este artículo, nos referiremos a dos: la seguridad y el combate contra el avance de la agenda de derechos de las minorías.

\section{LA SEGURIDAD}

Tradicionalmente preocupada por la seguridad, como un aspecto central constitutivo de su cosmología ideológica, la derecha encontró en las políticas del Frente Amplio, razones objetivas para construir un discurso opositor consistente y vinculado con las preocupaciones cotidianas de la población. Durante el gobierno de FA, los delitos contra la propiedad, tales como rapiñas y hurtos, y contra la vida, sufrieron un fuerte incremento. Los últimos datos del Ministerio del Interior, de 2018 (LAS RAPIÑAS..., 2019), muestran un incremento del $53,8 \%$ en el número de rapiñas, respecto al año anterior, y de $45,8 \%$ en el número de homicidios. Del total de homicidios, el $60 \%$ corresponden a casos de "conflicto criminal", lo que da cuenta de la extensión y penetración de las bandas ligadas al tráfico de drogas. El incremento en la tasa de homicidios se multiplicó por seis respecto a 2017 y 2016 . Estos datos hacen ascender la tasa de homicidios en Uruguay a 11,2 cada cien mil habitantes, y a 15,4 cada cien mil en Montevideo, lo que lo sitúa, según la Organización Mundial de la Salud en situación de "epidemia de homicidios" (URUGUAY..., 2019). Las tasas uruguayas superan a las de países como Argentina y Chile, pero también con países tradicionalmente más violentos, como Bolivia, Ecuador y Paraguay, entre otros. El rating de los países más violentos de la región lo encabeza Venezuela, seguido de Brasil. 
Las causas de este fenómeno son complejas, y no cabe analizarlas en un artículo sobre educación. Sin embargo, no es posible dejar de atender a la incidencia, aunque sea mínima, de la socialización en unos valores culturales de cierta izquierda, sobre todo la proveniente del movimiento tupamaro, respecto a la concepción del delito y de la pobreza. Si se parte de la idea de que toda propiedad es un robo, o que robar es una forma de expropiación -como sostiene el exdirigente tupamaro Zabalza (ANTE..., 2017), luego de haber admitido que los tupamaros se financiaron mediante robos durante el períodos post dictadura a través de las "tupabandas" (URRUZOLA, 2017; GARCÉS, 2011)- o, en sus versiones menos radicales, que las personas sólo roban para satisfacer necesidades básicas, la consecuencia más probable es la erosión de la convicción sobre la corrección y legitimidad de la punición de los comportamientos delictivos.

Cuando las políticas de redistribución económica aplicadas por la izquierda lograron reducir la pobreza a menos del $10 \%$, y casi hacen desaparecer la indigencia, mientras el incremento del delito se seguía acelerando, la relación de causalidad entre pobreza o necesidad y delito, entró en cuestión. Del lado del Ministerio de Interior lencargado de la seguridad interna) se habían centrado los esfuerzos en la tecnificación de la policía, pero no en el ataque frontal de las redes delictivas vinculadas con el tráfico de drogas, y la violencia privada. Sólo en el último año, el Ministerio asumió políticas de intervención urbana, demoliendo los principales enclaves de distribución de drogas, y procesando a sus responsables. La derecha, encontró a estas medidas, tibias y tardías. Cierta izquierda también arrojó abrió fuego contra estas medidas: eran vistas como violentas y como una forma de "estigmatizar la pobreza". Para el siguiente gobierno, el candidato del Frente Amplio, Daniel Martínez, llegó a designar al encargado de estos operativos, el sociólogo Gustavo Leal, como su asesor en temas de seguridad.

Junto con los partidos políticos tradicionales blancos y colorados, en general partidos catch all, ${ }^{6}$ ha surgido, este año, un partido explícitamente de derecha: Cabildo Abierto, liderado por el ex Comandante en Jefe del Ejército, nombrado en el gobierno de Mujica, el General Guido Manini Ríos. Sin internas que disputar, porque era el único candidato de su partido, Manini obtuvo un 5\% de votos en las elecciones internas de junio de 2019 , y las encuestadoras le asignaron una intención de voto de hasta $10 \%$ en las elecciones nacionales de octubre del mismo año. ${ }^{7}$

\footnotetext{
6 Se llama así a los partidos que abarcan un espectro amplio del electorado, desde posturas más conservadoras, hasta más progresistas. La fuerza relativa de las tendencias, en cada partido, está dada por la correlación de fuerzas entre los distintos sectores dentro de ellos.

7 El partido de Manini Ríos, Cabildo Abierto, superó el 11\% de los votos, situándose como cuarto partido en número de votantes después del Frente Amplio (39\%), y los partidos tradicionales Nacional (29\%) y Colorado (12\%). Obtuvo 3 Senadores (en 30) y 11 Diputados (en 99) (ELECCIONES..., [2020?]).
} 
La derecha se ha encontrado, en este nuevo panorama de violencia y temor ciudadano, como pez en el agua y ha conseguido, con la invalorable colaboración de la izquierda, el principal argumento para volver al poder: el restablecimiento del orden.

\section{EL COMBATE DEL AUANCE DE LA AGENDA DE DERECHOS DE LAS MINORÍAS}

La labor legislativa de la izquierda fue prolífica en normas en beneficio de las minorías y en el reconocimiento de la nueva agenda de derechos. Durante los gobiernos de FA, se aprobaron, por ejemplo, las siguientes leyes: Ley de matrimonio igualitario, ley de atención integral a las personas trans, de derecho a la identidad sexual, ley de interrupción voluntaria del embarazo, ley contra la violencia hacia las mujeres basada en género, ley de cuotas, ley de prevención y combate a la trata y explotación de personas, ley de acceso a la información pública, ley de producción, ley de distribución y venta del cannabis, extensión de las licencias por maternidad y paternidad. Excepto la última, todas ellas, incluso tomadas por separado, son suficientes para enervar las defensas de cualquier representante de la derecha, ya que todas ellas ponen en cuestión aquello en lo que la derecha cree: la existencia de un "orden natural".

En el país más secular de América Latina, donde el porcentaje de católicos iguala al de ateos (28\%) entre los menores de 35 años (LOS URUGUAYOS..., 2019), la derecha se encuentra desprovista de la capacidad de impugnar, con éxito, el derecho universal a la disposición sobre su cuerpo de las mujeres, o el derecho a la igualdad ante la ley de los homosexuales a la hora de contraer matrimonio, o de los trans a elegir su identidad sexual. Cada ataque contra esos colectivos, contribuye a victimizarlos, y tiene el efecto paradójico de fortalecer la simpatía hacia sus problemáticas. Invirtiendo la estrategia, la derecha elige convertirse en víctima:

\footnotetext{
Para la derecha vivimos en una dictadura: la dictadura de lo politicamente correcto. No se puede hablar, no se puede pensar, por miedo a ser perseguido por una horda de focas estalinistas, travestis ideológicos, defensores de los delincuentes, feminazis malcogidas, cornudos contumaces, tontos útiles de la pederastía, bufarrólogos, comunistas con el dinero ajeno, putos del culo, ovejas que siguen dócilmente a demagogos adoctrinantes financiados por oscuros y misteriosos reptilianos millonarios. La respuesta indignada y violenta frente a este panorama se autodenomina "incorrección política", como forma de ejercer la libertad en medio del autoritarismo. [...] La incorrección [...] se trata cada vez más de un dispositivo que esconde lealtad a los códigos y los valores de siempre, que permite desplazar la frontera de
} 
lo decible, y devolver al centro de la escena política al fascismo, la xenofobia, la misoginia y el racismo, que la izquierda ingenuamente creyó derrotados en anteriores batallas. (ENTRE, 2019, p. 152-153).

El siguiente ejemplo puede darnos una idea del tipo de luchas que puede entablarse como reacción a una legislación que contradice lo que es, para la derecha, el "orden natural".

En febrero de 2017, una mujer oriunda de una ciudad del interior del país, inicia los trámites oficiales para interrumpir voluntariamente el embarazo que resultó de una relación ocasional con un conocido. El hombre, que no mantenía una relación afectiva con la mujer, consideró que con el aborto se afectaba su derecho a decidir si ese hijo debía nacer o no. Consiguió un abogado patrocinante e introdujo una acción de amparo para que la mujer no pudiera practicarse el aborto. La jueza, curiosamente de nombre Pura Concepción Book, católica declarada, hizo lugar a la demanda. Mientras tanto, los plazos legales para interrumpir el embarazo, que es de doce semanas, seguían corriendo (PURA..., 2017).

La derecha asumió el caso como una causa propia. Las redes sociales ardían con las palabras exaltadas de los conservadores que se sentían personalmente afectados por el desconocimiento del derecho del hombre, a decidir sobre la mujer y sobre el embrión. Los argumentos, débilmente manejados, iban en la dirección de reivindicar el derecho del hombre a decidir sobre su paternidad, tras lo que se escondía la indignación por la pérdida central de la tutela masculina sobre la mujer. La pretensión, era que ya que el hombre se haría responsable de la manutención del embrión, en caso de nacer, la vida de la mujer quedara, de ahí en más, subordinada a las necesidades del embrión, y vigilada para que sus acciones u omisiones, durante el embarazo, no comprometieran la viabilidad del mismo. Era, en suma, quitar a la mujer su capacidad jurídica para decidir sobre sobre lo más elemental: qué comer o beber, cómo transportarse, etcétera, como si fuera literalmente, incapaz. Lo que hay, se decía, es un vacío legal: el Parlamento olvidó contemplar el derecho del hombre. Pero tal vacío legal, realmente, es inexistente. La legislación establece, con claridad, que la mujer embarazada y sólo ella, tiene potestad para decidir, dentro de los plazos y requisitos legales, si seguirá o no adelante con la preñez. Si el hombre no tiene lugar en la ley, es porque nunca se quiso que lo tuviera. De eso se trata una ley que se llama, ni más ni menos “Ley de interrupción voluntaria del embarazo"; voluntaria, o sea, según la voluntad de quien procesa ese embarazo.

Mientras el expediente se trasladaba al Tribunal de Apelaciones, la mujer sufrió un aborto espontáneo, debido a una lesión uterina sobre la que ya había advertido. Pero se descontaba que el Tribunal de Apelaciones revocaría la decisión de Pura Concepción. Aunque la mujer había sido identificada, acosada, llevada a tribunales, perseguida por la prensa, enjuiciada públicamente, condenada y señalada con el dedo por toda la timorata sociedad de su ciudad de residencia, para la derecha, la única víctima, era el padre. Aun perdidosos, la derecha había dado su batalla, con valentía y autenticidad. No era que hubieran 
criminalizado a una mujer en el ejercicio legítimo de sus derechos. Para ellos, enfrentar a toda la colectividad de "feminazis", "desnaturalizadas" e "insensibles", aún a riesgo de quedar como "políticamente incorrectos", era un mérito y un signo de coraje y autenticidad. No, no eran reaccionarios; eran auténticos:

\footnotetext{
la incorrección política se presenta como el discurso no hipócrita ni falso, sino sincero, que a fin de cuentas, en el acierto o en el error, dice lo que piensa y no lo impuesto por el poder. Desde su autopercepción, la incorrección política es la única que se anima a decir la verdad. En última instancia, decir que algo es políticamente correcto es decir que aunque suene bien, en el fondo es falso; mientras que decir que algo es políticamente incorrecto es decir que aunque suene mal, en el fondo es verdadero. (ENTRE, 2019, p. 155).
}

Como se ha podido comprobar en procesos electorales recientes, la incorrección política es la llave que abre las puertas del gobierno a la nueva derecha mediática. Primero Donald Trump en Estados Unidos, luego Jair Bolsonaro en Brasil, nos han enrostrado el modo cómo se puede llegar a la presidencia de los mayores países del continente, a lomos del insulto a las minorías: mexicanos, latinos, inmigrantes, homosexuales, negros, mujeres, todos cayeron bajo los ataques desmesuradamente violentos de dos hombres de derecha. Frente a los ojos incrédulos de políticos profesionales, intelectuales, ciudadanos informados y amantes de la república, los insultos contra las minorías resultaron ser, para ciertas capas sociales, las palabras que estaban esperando oír, tal vez frustrados y resentidos por la eterna postergación de la que se sentían víctimas, y recientemente agraviados por la humillación que suponía aceptar a los negros, a las mujeres, a los homosexuales, latinos, como sus iguales, con iguales derechos. "No. Basta de corrección política y de hipocresía, volvamos al orden natural de las cosas. Ahí hay un hombre auténtico, que no miente, y que dice lo que realmente piensa y siente. Yo Voto a Trump/Voto a Bolsonaro". Ese es el mensaje que suele cultivar la nueva derecha en ascenso.

\section{CONCLUSIÓN: LA EDUCACIÓN SABOTEADA Y OTRAS PARADOJAS DE CIERTA IZQIERDA}

¿̇ué tienen en común Manini Ríos, los resultados de la educación, el aumento del delito, los títulos robados y el viru viru? Aparentemente nada, posiblemente mucho.

La segunda acepción que la Real Academia de la lengua española de la palabra "sabotaje" -que he elegido, en su forma verbal, como título de este artículo- significa "oposición u obstrucción disimulada contra proyectos, órdenes, decisiones, ideas, etc." (REAL ACADEMIA 
ESPAÑOLA, 2019). De la definición, me quedo con cuatro palabras: obstrucción disimulada contra proyectos. Eso es lo que, a mi juicio, ha venido haciendo cierta izquierda, en contra del proyecto del Frente Amplio en general, y de su proyecto educativo en particular. A través de una permanente y continuada acción de descrédito de las políticas del FA y de su eficacia, disimulada tras formas aparentemente populares de ver el mundo y de comportarse en él, cierta izquierda ha ido erosionando la convicción de que la izquierda puede hacer cambios importantes en la sociedad, aún en aquellos campos que más aprecia la derecha: la seguridad, el honor social, la dignidad de la educación, y el respeto mutuos. Con ello, ha facilitado el ascenso de cuadros y de discursos abiertamente derechistas, que pretenden disputar el poder político -y probablemente lo logren- a la izquierda oficialista. ${ }^{8}$

Para dar respuesta a la pregunta que daba inicio a este apartado: El general Guido Manini Ríos fue ascendido como Comandante en Jefe del Ejército por el Presidente José Mujica, en 2015. Mujica, que se opuso al juzgamiento de los responsables de los delitos de lesa humanidad que se cometieron durante la dictadura, bajo el pretexto de que son "unos viejitos", y que propuso hacer un monumento a la reconciliación con las fuerzas armadas, sin haber hecho lo necesario para sacar a luz los hechos delictivos de estas fuerzas durante la dictadura, hizo todo lo posible por cultivar la mejor relación con sus antiguos captores, a quienes tiende a ver, como simples combatientes, como simples miembros de un ejército al que había combatido y que lo había derrotado. Las buenas relaciones entre el sector mujiquista y las fuerzas armadas, han tenido múltiples manifestaciones (TOPOLANSKY..., 2012; YANES, 2019).

Durante los gobiernos del FA, Mujica se reservó para sí la designación de las autoridades para al menos tres áreas clave: a) Las fuerzas armadas, a las que se propuso cooptar, para lo cual designó como Ministro de Defensa Nacional a su viejo compañero de armas en el movimiento tupamaro, Eleuterio Fernández Huidobro, hoy fallecido, quien aseguró impunidad a los responsables de terrorismo de estado. La derecha, agradecida. b) La seguridad interna, o sea, la policía, y colocó en esa cartera ministerial a Eduardo Bonomi, otro ex tupamaro, que cumplió dos períodos completos como Ministro del Interior (10 años) a pesar de que su gestión muestra el más acelerado incremento de todos los tipos de delitos de la historia del país. La derecha, agradecida. c) La educación, y en especial la educación básica, donde logró colocar a representantes de su movimiento en los tres períodos de gobierno del FA. Primero, el inmunólogo amazónico, y tras un breve interregno en que se hizo cargo de la ANEP un ex decano de la Facultad de Humanidades y Ciencias de la Educación, a Wilson Netto, que va a cumplir ocho años al frente del principal organismo de gobierno de la educación. Los resultados de su gestión, están a la vista. La derecha, una vez más, agradecida.

8 Este artículo fue escrito con anterioridad a las elecciones nacionales de 2019, en las que triunfó la oposición, en una coalición multipartidaria que agrupa a partidos y sectores con orientaciones diversas. Como se vio, la predicción no estaba desencaminada. Como consecuencia de este y otros factores, el ascenso de las fuerzas opositoras a las políticas del FA, era visible desde al menos, junio de 2019. 
En los ámbitos de actividad política controlada por jerarcas de la confianza de Mujica, es donde la izquierda muestra sus mayores debilidades y son, curiosamente también, las áreas que más anhela controlar la derecha: Las fuerzas armadas y la policía para asegurar el orden, haciendo uso legítimo de la fuerza que tiene el estado, y la educación, que se encarga de la transmisión de los conocimientos, de las ideas, de las perspectivas de ver el mundo que han de prevalecer en una sociedad. Las ciencias sociales y humanas, es decir, las ciencias críticas por excelencia, han sido erosionadas por el descrédito a que las ha sometido el "viru viru"; los títulos universitarios y académicos, bastardeados; la tarea legislativa, devaluada. Nada de esto es parte de un proyecto de izquierda, sino al contrario, de derecha: aquel que prefiere a la gente pobre y pobre para siempre, aquel que prefiere a la gente poco instruida y poco crítica, aquel que prefiere ser amigo de la fuerza física y de las armas, aquel que prefiere el despotismo a la república, aquel que erige al líder carismático y reniega de las instituciones.

Muchas otras cosas, distintas y opuestas hay en el Frente Amplio, y por todas ellas hemos podido, los uruguayos, disfrutar de la mejor distribución de ingreso de América Latina, ser la única democracia plena de Sudamérica, tener una bajisima tasa de mortalidad infantil, contar con Consejos de Salarios y negociaciones tripartitas, y tantos otros beneficios que hoy quedan relegadas por una gestión de izquierda que es necesario revisar.

A los ojos del mundo, esta última no es, sin embargo, la mejor versión de la izquierda. La mejor versión es la otra, la del viru viru: la que, saboteando el proyecto frenteamplista tiende, generosamente, a la derecha, una alfombra roja.

\section{REFERENCIAS}

A PROPÓSITOS de dichos de Leo Masliah. Asociación ટ̇Dónde Están?, 15 sept. 2016. Disponible en: https:// donde-estan.com/2016/09/15/a-propositos-de-dichos-de-leo-masliah/. Acceso en: 12 marzo 2020.

ANTE versiones de que el MPP robó en los 90, Zabalza reconoció que usaron formas "alternativas" para financiarse. El observador, 25 abr. 2017. Disponible en: https://www.elobservador.com.uy/nota/ ante-versiones-de-que-el-mpp-robo-en-los-90-zabalza-reconocio-que-usaron-formas-alternativas-para-financiarse-201742510500. Acceso en: 5 fev. 2020.

CEPAL. Enseñanza primaria y ciclo básico de educación media en el Uruguay. Montevideo: CEPAL, 1990.

CIDE-CCEE. Informe sobre el estado de la educación en Uruguay. Montevideo: Ministerio de Instrucción Pública y Previsión Social, 1965.

CONVOCARÁN al Parlamento a Lorenzo y Pintado por caso Pluna. Subrayado, 4 oct. 2012. Disponible en: https://www.subrayado.com.uy/convocaran-al-parlamento-lorenzo-y-pintado-caso-pluna-n17227. Acceso en: 8 mayo 2020 
ELECCIONES generales de Uruguay de 2019. Wikipedia, [20202]. Disponible en: https://es.wikipedia.org/ wiki/Elecciones_generales_de_Uruguay_de_2019. Acceso en: 8 mayo 2020.

EL PAíS “tiene espalda" para soportar una choque financiero externo. 180, 4 agosto 2014. Disponible en: https://www.180.com.uy/articulo/40985_El-pais-tiene-espalda-para-soportar-una-choque-financiero-externo. Acceso en: 12 marzo 2020.

ENTRE. La reacción. Derecha e incorrección política en Uruguay. Montevideo: Estuario Editora, 2019.

GARCÉS, A. Donde hubo fuego. Montevideo: Fin de Siglo, 2011.

GRACIELA VILLAR sobre su presentación como psicóloga social: "Puede ser un error". El observador, 8 jul. 2019. Disponible en: https://www.elobservador.com.uy/nota/graciela-villar-sobre-su-presentacion-como-psicologa-social-puede-ser-un-error--20197820573. Acceso en: 6 abr. 2020.

"HAY QUE educar en el respeto de las raices, manteniendo valores y responsabilidad". Uruguai Presidencia, 15 agosto 2014. Disponible en: https://www.presidencia.gub.uy/comunicacion/comunicacionnoticias/mujica-utu-santa-ana-educacion-valores-responsabilidad. Acceso en: 12 marzo 2020.

INEED. Informe sobre el estado de la educación en Uruguay 2017-2018. Montevideo: INEEd, 2019.

MADRID, P.; RUGGIERO, V. Sendic. La carrera del hijo pródigo. Montevideo: Planeta, 2017.

LA FACULTAD de criticar. Mujica apuntó contra el país académico. Montevideo Portal, 21 nov. 2011. Disponible en: https://www.montevideo.com.uy/Noticias/Mujica-apunto-contra-el-pais-academico-uc253525. Acceso en: 6 abr. 2020.

LA MTAD de los nuevos parlamentarios en Uruguay no tiene título universitario. Infobae, 9 nov. 2014. Disponible en:

https://www.infobae.com/2014/11/09/1607647-la-mitad-los-nuevos-parlamentarios-

-uruguay-no-tiene-titulo-universitario/. Acceso en: 25 marzo 2020.

LAS RAPIÑAS crecieron 53,8\% y los homicidios 45,8\% en 2018 con respecto al año 2017 . El observador, 25 marzo 2019. Disponible en: https://www.elobservador.com.uy/nota/las-rapinas-crecieron-53-8-y-los-homicidios-45-8-en-2018-con-respecto-al-ano-2017-201932519340. Acceso en: 6 abr. 2020.

LOS URUGUAYOS y la religión. Opcion consultores, 7 feb. 2019. Disponible en: http://www.opcion.com.uy/ opinion-publica/los-uruguayos-y-la-religion/. Acceso en: 25 marzo 2020.

MARRERO, A. La herencia de nuestro pasado en "El Uruguay del Siglo XX. La sociedad". Montevideo: EBO, 2008.

MRZA, C. Patologías de la izquierda. Claves para superarlas. Montevideo: Fundación de Cultura Universitaria, 2019. 
MUJICA A LOS maestros: sí, ganan poco; trabajen más. El observador, 22 jul. 2013. Disponible en: https://www.elobservador.com.uy/nota/mujica-a-los-maestros-si-ganan-poco-trabajen-mas-20137227560. Acceso en: 25 marzo 2020.

MUJICA ACLARÓ criticas sobre escribanos, abogados y economistas. Subrayado, 3 abr. 2013. Disponible en: https://www.subrayado.com.uy/mujica-aclaro-criticas-escribanos-abogados-y-economistas-n22236. Acceso en: 25 marzo 2020.

MUJICA: "Estamos infectados de economistas y escribanos". Subrayado, 17 marzo 2013. Disponible en: https://www.subrayado.com.uy/mujica-estamos-infectados-economistas-y-escribanos-n21790. Acceso en: 12 marzo 2020.

NEIRA, T. La cultura contra la escuela. Barcelona: Ariel, 1999.

PURA Concepción Book: «Todo va a hacerse antes de las 12 semanas de gestación». LaRed21, 1 marzo 2017. Disponible en: https://www.lr21.com.uy/justicia/1323677-pura-concepcion-book-aborto-mercedes-apelacion-plazo. Acceso en: 6 abr. 2020.

RAMA, G. Situación de la enseñanza primaria y media. Montevideo: AAVV, 1971.

REAL ACADEMIA ESPAÑOLA. Sabotaje. Madrid: REA, 2019. Disponible en: https://dle.rae.es/srv/ search? $\mathrm{m}=30 \& w=$ sabotaje. Acceso en: 14 marzo 2020.

TOPOLANSKY insistió con la fidelidad de las Fuerzas Armadas y los militares se molestaron. Uy.press, 5 mayo 2012. Disponible en: https://www.uypress.net/auc.aspx?27891. Acceso en: 5 fev. 2020.

URRUZOLA, M. Eleuterio Fernández Huidobro. Sin remordimientos. Montevideo: Planeta, 2017.

URUGUAY enfrenta "epidemia de asesinatos" y supera a la mayoría de paises de la región. El observador, 9 enero 2019. Disponible en: https://www.elobservador.com.uy/nota/uruguay-enfrenta-epidemia-de-asesinatos- ${ }^{-}$-supera-a-la-mayoria-de-paises-de-la-region-20191818287\#_=_. Acceso en: 6 abr. 2020.

"VIRU VIRU" tu madrina. Mediorama, 26 nov. 2011. Disponible en: http://mediorama.blogspot.com/2011/11/ viru-viru-tu-madrina.html. Acceso en: 14 marzo 2020.

YANES, H. Guiños políticos del MPP a Manini Ríos. Laizquierda Diario, 28 jul. 2019. Disponible en: http:// www.laizquierdadiario.com.uy/Guinos-politicos-del-MPP-a-Manini-Rios. Acceso en: 21 marzo 2020.

Endereço para correspondência: Avenida 18 de Julio १८२4-१८50, १२०० Montevideo, Uruguai; adriana. marrero.fernandez@gmail.com.

Roteiro, Joaçaba, U. 45, p. 1-26, jan./dez. 2020 | e23088 |E-ISSN 2177-6059 